\title{
PENGARUH FAKTOR EKOLOGI TERHADAP RESILIENSI REMAJA
}

\author{
Euis Sunarti ${ }^{\left.{ }^{*}\right)}$, Intan Islamia ${ }^{2}$, Nur Rochimah ${ }^{3}$, Milatul Ulfa $^{1}$ \\ ${ }^{1}$ Departemen IImu Keluarga dan Konsumen, Fakultas Ekologi Manusia, Institut Pertanian Bogor, \\ Bogor 16680, Indonesia \\ ${ }^{2}$ Departemen Bimbingan dan Konseling Islam, UIN Raden Intan Lampung, Lampung 35131, Indonesia \\ ${ }^{3}$ Departemen Pendidikan Guru Raudhatul Athfal, STAI Bani Saleh Bekasi, Bekasi Timur 17113, Indonesia \\ "E-mail: euissunarti@apps.ipb.ac.id; euisnm@gmail.com
}

\begin{abstract}
Abstrak
Remaja masa kini semakin dituntut untuk memiliki resiliensi agar dapat mencegah terganggunya tugas perkembangan, kualitas hidup, serta masa depan mereka. Penelitian ini bertujuan untuk mengelaborasi resiliensi remaja dan faktor ekologis yang memengaruhinya. Menggunakan desain kuantitatif, penelitian ini dilakukan dalam rentang waktu September 2015 hingga Januari 2016. Total contoh penelitian sebanyak 120 remaja diperoleh melalui teknik multi-stage random sampling. Data primer dikumpulkan melalui metode survei dengan menggunakan kuesioner yang dikembangkan oleh peneliti. Hasil penelitian menunjukkan bahwa faktor-faktor ekologi remaja seperti kesejahteraan subjektif, faktor protektif internal (termasuk penerimaan diri, penerimaan lingkungan, kepercayaan diri, prestasi, disiplin, dan kemampuan diri), faktor protektif eksternal (termasuk protektif pengasuhan, protektif keluarga, protektif sekolah, protektif teman, dan protektif masyarakat), keterlibatan remaja dalam perilaku kenakalan remaja, pendapatan keluarga, lama pendidikan ayah, wilayah administratif dan tipe sekolah berhubungan dengan resiliensi remaja. Lebih jauh, faktor protektif sekolah, faktor protektif pengasuhan, dan faktor protektif internal remaja berpengaruh positif yang signifikan terhadap resiliensi remaja. Analisis regresi linear berganda yang dilakukan terhadap faktor protektif keluarga dan resiliensi remaja menunjukkan bahwa orientasi moral-religi, kohesi, dan orientasi prestasi berpengaruh positif yang signifikan terhadap resiliensi remaja.
\end{abstract}

Kata kunci: faktor ekologi, faktor protektif, remaja, resiliensi

\section{The Influence of Ecological Factors on Youth Resiliency}

\begin{abstract}
Youth nowadays are increasingly required to have a resiliency in order to prevent disturbance in their developmental task, quality of life, and their future. This research aimed to elaborate youth resiliency and influence of ecological factors on their resiliency. Using quantitative design, this research was conducted during September 2015 - January 2016. Total 120 teenagers were generated through multi-stage random sampling technique. Primary data was collected through survey using researcher-developed questionnaire. Results showed that youth ecological factors such as subjective well-being, internal protective factor (including self-acceptance, environment acceptance, self-confidence, achievement, discipline, self-ability), external protective factors (including parenting, family, school, peer group, and society environment), involvement of children in juvenile delinquency, family income, father's length of education, administrative areas, and types of schools were associated with youth resiliency. Furthermore, external protective factors (from school, and parenting), and youth internal protective factors have a positive significant effect on youth resiliency. Specific regression analysis the influence family protective factor on youth resiliency showed that moral-religious orientation, cohesion, and achievement orientation have a positive significant effect on youth resiliency.
\end{abstract}

Keywords: ecological factors, protective factors, resiliency, youth

\section{PENDAHULUAN}

Masa remaja merupakan masa peralihan atau transisi yang penuh dengan gejolak pencarian identitas diri (Monks, 1987). Gunarsa dan Gunarsa (2003) menjelaskan bahwa dalam memenuhi pencarian identitas dirinya, remaja berkenalan dengan berbagai hal baru yang dapat menyebabkan kegoncangan dan mengarahkan kepada terjadinya krisis identitas. Remaja masa kini semakin menghadapi dinamika kehidupan akibat perubahan sosial ekonomi, perkembangan informasi, dan teknologi juga globalisasi. Oleh karenanya, remaja dituntut memiliki resiliensi agar tidak mengalami kondisi yang akan mengganggu tugas perkembangan, kualitas hidupnya, dan masa depannya kelak. Dalam upaya pembangunan kualitas remaja, saat ini telah diketahui bahwa terdapat berbagai 
macam masalah yang dihadapi remaja Indonesia. Data Komnas Perlindungan Anak menunjukkan jumlah perokok di bawah usia 18 tahun antara tahun 2004 hingga Maret 2012 sebanyak 28 juta orang, pada tahun 2012 terdapat 2238 tersangka pengguna dan pengedar narkoba yang berusia kurang dari 19 tahun, dan pada tahun 2010-2012 terjadi 301 kali tawuran pelajar di Jabodetabek.

Mengingat remaja merupakan generasi muda yang memiliki peran strategis, salah satu bentuk perlindungan khusus kepada remaja yang penting dilakukan seluruh pihak adalah melalui pencegahan, yaitu dengan membangun resiliensi sehingga remaja memiliki kemampuan dalam mencegah, mengantisipasi, beradaptasi, dan menghadapi masalah yang dihadapi. Resiliensi diartikan sebagai kemampuan mengembalikan diri dari kesulitan dan perubahan yang terjadi kepada fungsi sebelumnya dan bergerak maju menuju perbaikan (Kalil, 2003). Resiliensi bukan sekedar atribut yang menetap, tetapi merupakan sebuah proses yang dipengaruhi oleh pengambilan keputusan sehari-hari (Masten, 2001 dalam LaFromboise et al., 2006). Wagnild dan Young (1993) mendefinisikan resiliensi sebagai karakteristik atau kemampuan untuk dapat mengatasi perubahan atau ketidakberuntungan, dengan kata lain kemampuan untuk bangkit serta melanjutkan kehidupan setelah jatuh dan terpuruk. Sementara Ungar (2008), Ungar dan Liebenberg (2011) mendefinisikan resiliensi sebagai kemampuan individu untuk memetakan sumberdaya dan bernegosiasi agar sumberdaya tersebut dapat tersedia melalui cara-cara yang dapat diterima secara budaya, yang menggambarkan ketersediaan dan aksesibilitas mereka dalam ekologis sosial dan fisik individu.

Teori sistem bio-sosial-ekologis mengenai perkembangan manusia diperkenalkan oleh Bronfenbrenner (1979) yang menjelaskan bahwa lingkungan memiliki efek yang besar terhadap perkembangan seseorang. Dalam kaitannya dengan resiliensi, proses menuju resiliensi juga merupakan proses dinamis dengan konstruksi multidimensi yang menggabungkan interaksi antara individu dan lingkungan mereka dalam beberapa konteks atau faktor ekologi yang mencakup faktor keluarga, teman sebaya, sekolah dan komunitas, serta lingkungan masyarakat (APA, 2008; Winfield, 1994). Dalam penelitian ini, faktor-faktor ekologi remaja dirinci mencakup faktor protektif internal dan eksternal, kesejahteraan subjektif, faktor risiko (keterpaparan dan keterlibatan remaja dalam perilaku kenakalan), pendapatan karakteristik remaja dan keluarga, wilayah administratif, dan tipe sekolah berhubungan dengan resiliensi remaja. Faktor risiko berkaitan dengan ancaman atau bahaya, kerentanan, keterpaparan terhadap bahaya, dan kapasitas mencegah atau mengelola ancaman. Sebaliknya, faktor protektif merupakan faktor yang bersifat menunda, meminimalisir atau bahkan menetralisir hasil akhir yang negatif, serta membantu melindungi remaja dari efekefek negatif faktor risiko. Benard (1995) membagi faktor protektif menjadi dua, yaitu: (1) faktor internal, terdiri atas kompetensi sosial (keterampilan sosial dan empati), keterampilan menyelesaikan masalah, otonomi, memiliki tujuan; dan (2) faktor eksternal, terdiri atas kesempatan untuk dapat berprestasi dalam aktivitas kelompok, hubungan yang hangat, dan harapan yang tinggi dari lingkungan. Faktor protektif eksternal juga menggambarkan sumberdaya yang dimiliki yang berasal dari keluarga dan organisasi sosial disekitarnya (Masten \& Coatsworth, 1998). Menurut Sunarti (2013a), kunci dari resiliensi seseorang dan keluarga adalah kemampuan mengelola dan memberdayakan aset yang dimiliki atau yang bisa diakses sehingga dapat menjadi faktor pelindung ketika menghadapi krisis.

Faktor protektif diantaranya interaksi kompleks antara faktor keluarga, proses dalam keluarga, proses sistem dalam diri individu, dan karakteristik individu (Resnick, 2000). Eriksson et al. (2010) mengemukakan bahwa faktor protektif dikelompokkan menjadi tiga yakni yang berasal dari: a) individu (internal) diantaranya kemampuan memecahkan masalah, kemampuan koping, orientasi sosial, inteligensi akademik, dan lain-lain; b) keluarga, diantaranya secure attachment, pengasuhan autoritatif, hubungan orang tua-anak yang baik, dukungan orang tua, dan lain-lain; c) lingkungan di luar keluarga, seperti sekolah, teman sebaya, kepercayaan terhadap agama, tetangga, intervensi sosial, dan sebagainya. The McCreatory Center Society (2006) melaporkan bahwa sebagian besar dari faktor protektif erat kaitannya dengan bentuk hubungan yang positif, misalnya meningkatkan kepedulian remaja terhadap keluarganya, meningkatkan keterampilan hidup, membuat perubahan pada lingkungan sekitarnya, maupun penurunan keterlibatan dalam perilaku berisiko. Namun faktor protektif remaja juga menghadapi berbagai macam faktor risiko dalam perjalanan menuju dewasa (Brooks, 2006). 
Faktor risiko merupakan prediktor awal dari sebuah hasil yang tidak menguntungkan dan sesuatu yang membuat orang menjadi rentan (Kaplan, 1999), termasuk diantaranya adalah faktor biologis dan faktor lingkungan. Sebagai contoh, remaja dari lbu yang adiksi terhadap obat-obatan terlarang memiliki kecenderungan untuk lahir disertai dengan masalah fisik dan emosional. Penelitian Hicks et al. (2013) menemukan bahwa kaitan antara genlingkungan dan perbedaan individu berkontribusi pada fase perkembangan awal yang berisiko tinggi bagi penyalahgunaan zat/obat pada remaja. Resiliensi juga berhubungan dengan kesejahteraan psikologis (Sagone \& De Caroli, 2014). Riset yang dilakukan terhadap orang usia dewasa menunjukkan bahwa terdapat hubungan signifikan antara tingkat resiliensi yang baik dengan kecenderungan kehidupan masa depan yang lebih baik, diantaranya yakni kesuksesan di masa tua, tingkat depresi yang lebih rendah, dan berumur panjang (MacLeod et al., 2016). Termasuk dalam faktor ekologi, yakni kesejahteraan subjektif, Berg et al. (2013) menyatakan bahwa banyaknya perubahan yang terjadi dalam kehidupan remaja sangat berpengaruh terhadap proses penyesuaian diri yang akhirnya berdampak pada kesejahteraan subjektif remaja. Dengan kata lain, kemampuan remaja dalam mengelola perubahan dalam hidupnya (resiliensi) berdampak pada kesejahteraan subjektif remaja.

Berdasarkan latar belakang dan berbagai kajian, maka peneliti memandang penting untuk melakukan penelitian mengenai faktor resiliensi remaja. Penelitian ini bertujuan untuk menganalisis hubungan karakteristik keluarga, keterlibatan dalam perilaku menyimpang, kesejahteraan subjektif, protektif internal, protektif pengasuhan orang tua, protektif keluarga, protektif sekolah, protektif teman, dan protektif masyarakat dengan resiliensi remaja. Penelitian ini juga bertujuan mengelaborasi faktor-faktor ekologis yang berpengaruh terhadap resiliensi remaja serta merumuskan rekomendasi upaya pembangunan resiliensi remaja.

\section{METODE}

Penelitian ini merupakan penelitian cross sectional dengan menggunakan desain kuantitatif. Penelitian dilakukan di SMA dan SMK di dua wilayah yaitu Kabupaten Bogor dan Kotamadya Depok. Penelitian ini dilakukan dalam rentang waktu September 2015 hingga Januari 2016.
Contoh penelitian adalah remaja kelas XI SLTA yang dipilih dengan menggunakan teknik multistage random sampling, yaitu penetapan Kabupaten Bogor dan Kotamadya Depok untuk mewakili perkembangan wilayah, SMA dan SMK pada masing-masing wilayah untuk mewakili keragaman lingkungan sekolah, dan keterwakilan jenis kelamin contoh. Sebanyak 120 contoh diperoleh hasil random dari hasil screening siswa yang memiliki faktor risiko yang cukup tinggi (berdasarkan tingkat keterpaparan siswa terhadap perilaku menyimpang atau kenakalan).

Data primer dikumpulkan menggunakan instrumen berupa kuesioner. Kuesioner yang digunakan berbentuk self-report yang diisi sendiri oleh contoh. Variabel yang diukur dalam kuesioner ini mencakup karakteristik remaja, karakteristik keluarga, keterpaparan, keterlibatan dalam perilaku menyimpang, masalah yang dihadapi remaja, ancaman, kesejahteraan subjektif, persepsi pengasuhan, resiliensi remaja, faktor protektif internal, faktor protektif lingkungan masyarakat, faktor protektif lingkungan sekolah dan faktor protektif lingkungan pertemanan. Jumlah pertanyaan pada variabel keterpaparan adalah 9 yang dijawab dengan pilihan ya (1) dan tidak (0). Variabel keterlibatan dalam perilaku menyimpang diukur dengan menggunakan 6 pertanyaan dengan jawaban ya (1) atau tidak (0).

Masalah yang dihadapi remaja diukur dengan Sembilan pertanyaan yang dijawab ya (1) dan tidak (0), contoh pertanyaan seperti sering terjadi pertengkaran di rumah, pernah ditinggal oleh orang yang dikasihi, pernah tinggal kelas, dan sebagainya. Variabel ancaman yakni berupa ajakan atau paksaan dari lingkungan untuk terlibat dalam perilaku kenakalan (misal: diajak merokok, dipaksa membolos, mencontek, miras, hubungan seks pranikah, dan sebagainya) diukur dengan menggunakan 12 pertanyaan (Jawaban ya $=1$ dan tidak $=0$ ). Kesejahteraan subjektif remaja diukur dengan menggunakan 4 pertanyaan dan jawaban skala Likert 1-5.

Pengukuran variabel protektif keluarga dilakukan dengan menggunakan kuesioner yang dimodifikasi dari Environment Scale (Moos \& Moos, 2009). Jumlah pertanyaan variabel protektif keluarga adalah 40 dengan jawaban menggunakan skala Likert 1-5. Varibel protektif pengasuhan orang tua diukur menggunakan 30 pertanyaan dan jawaban menggunakan skala Likert 1-5. Instrumen resiliensi (18 pertanyaan), faktor protektif 
internal (6 pertanyaan), faktor protektif lingkungan masyarakat (10 pertanyaan), faktor protektif lingkungan sekolah (10 pertanyaan) dan faktor protektif lingkungan pertemanan (10 pertanyaan) dimodifikasi dari The Resilience and Youth Development Module (RYDM) dengan pilihan jawaban menggunakan skala Likert 1-5. Skor yang diperoleh kemudian dikonversi dalam bentuk persen $(0,00-100,00)$, semakin tinggi skor menunjukkan semakin tinggi variabel tersebut dialami atau dimiliki oleh contoh.
Data yang telah dikumpulkan dianalisis secara deskriptif dan inferensial. Analisis deskriptif dilakukan untuk memberikan gambaran sebaran contoh berdasarkan variabel, wilayah administratif, jenis kelamin, dan jenis sekolah. Analisis inferensial yang dilakukan dalam penelitian ini adalah uji korelasi Spearman untuk melihat hubungan antar variabel. Selanjutnya dilakukan analisis regresi linear berganda digunakan untuk menganalisis faktor-faktor yang berpengaruh terhadap resiliensi remaja.

Tabel 1 Karakteristik orang tua dan keluarga

\begin{tabular}{|c|c|c|c|c|c|c|c|}
\hline \multirow{2}{*}{ Kategori } & \multirow{2}{*}{ Total (\%) } & \multicolumn{2}{|c|}{ Wil. Administratif (\%) } & \multicolumn{2}{|c|}{ Jenis Kelamin (\%) } & \multicolumn{2}{|c|}{ Jenis Sekolah (\%) } \\
\hline & & Kabupaten & Kota & Perempuan & Laki-Laki & SMK & SMA \\
\hline \multicolumn{8}{|l|}{ Usia Ayah } \\
\hline Rata-rata & 43,19 & 40,10 & 46,28 & 44,42 & 41,97 & 41,21 & 45,79 \\
\hline Min-Maks & $33-75$ & $33-65$ & $37-75$ & $33-75$ & $35-64$ & $33-75$ & $35-65$ \\
\hline \multicolumn{8}{|l|}{ Usia Ibu } \\
\hline Rata-rata & 41,02 & 39,15 & 42,88 & 41,60 & 40,43 & 40,09 & 42,23 \\
\hline Min-Maks & $24-57$ & $24-57$ & $30-56$ & $24-55$ & $30-57$ & $30-57$ & $24-56$ \\
\hline \multicolumn{8}{|c|}{ Pendidikan Ayah (Tahun) } \\
\hline Rata-rata & 9,89 & 7,40 & 12,38 & 10,03 & 9,75 & 8,66 & 11,50 \\
\hline Min-Maks & $2-20$ & $2-16$ & $6-20$ & $5-16$ & $2-20$ & 3-16 & $2-20$ \\
\hline \multicolumn{8}{|c|}{ Pendidikan Ibu (Tahun) } \\
\hline Rata-rata & 9,75 & 8,00 & 11,50 & 9,87 & 9,63 & 8,63 & 11,21 \\
\hline Min-Maks & 3-16 & $3-16$ & $5-16$ & $3-16$ & $3-16$ & $4-16$ & $3-16$ \\
\hline \multicolumn{8}{|c|}{ Besar Keluarga (Orang) } \\
\hline Rata-rata & 4,81 & 4,95 & 4,67 & 4,90 & 4,72 & 4,91 & 4,67 \\
\hline Min-Maks & $2-11$ & $2-11$ & $2-9$ & $2-11$ & $3-8$ & $2-11$ & $2-8$ \\
\hline \multicolumn{8}{|l|}{ Keutuhan Keluarga } \\
\hline Tidak Utuh & 15,8 & 20,0 & 11,7 & 16,7 & 15,0 & 16,2 & 15,4 \\
\hline Utuh & 84,2 & 80,0 & 88,3 & 83,3 & 85,0 & 83,8 & 84,6 \\
\hline \multicolumn{8}{|c|}{ Pendapatan Per Kapita (Ribu Rupiah) } \\
\hline Rata-rata & $1.061,6$ & 582,26 & $1.541,01$ & 1177,83 & 945,4 & 601,27 & $1.663,65$ \\
\hline Min-Maks & $\begin{array}{c}83,3- \\
18.333,3\end{array}$ & $83,3-3.250$ & $\begin{array}{c}83,3- \\
18.333,3\end{array}$ & $\begin{array}{c}83,3- \\
18.333,3\end{array}$ & $\begin{array}{l}112,5- \\
8.000\end{array}$ & $\begin{array}{c}83,3- \\
4.166,67\end{array}$ & $\begin{array}{c}125- \\
18.333,3\end{array}$ \\
\hline \multicolumn{8}{|c|}{ Kategori Kemiskinan ${ }^{1}$} \\
\hline Miskin & 30,0 & 46,7 & 13,3 & 25,0 & 35,0 & 32,4 & 26,9 \\
\hline Tidak Miskin & 70,0 & 53,3 & 86,7 & 75,0 & 65,0 & 67,6 & 73,1 \\
\hline \multicolumn{8}{|l|}{ Status bekerja ibu } \\
\hline Tidak bekerja & 74,2 & 81,7 & 66,7 & 70,0 & 78,3 & 83,8 & 61,5 \\
\hline Bekerja & 25,8 & 18,3 & 33,3 & 30,0 & 21,7 & 16,2 & 38,5 \\
\hline \multicolumn{8}{|c|}{ Jenis Pekerjaan Ayah } \\
\hline Buruh & 18,3 & 23,3 & 13,3 & 16,7 & 20,0 & 22,1 & 13,5 \\
\hline Wiraswasta & 40,0 & 48,3 & 31,7 & 38,3 & 41,7 & 38,2 & 42,3 \\
\hline PNS, TNI/ABRI & 4,1 & 0,0 & 8,4 & 1,7 & 6,7 & 3,0 & 5,8 \\
\hline Pegawai Swasta & 17,5 & 0,0 & 35,0 & 18,3 & 16,7 & 17,6 & 17,3 \\
\hline $\begin{array}{l}\text { Profesi (Pengacara, } \\
\text { dosen, guru) }\end{array}$ & 1,7 & 1,7 & 1,7 & 3,3 & 0,0 & 0,0 & 3,8 \\
\hline $\begin{array}{l}\text { Lainnya (ojek, } \\
\text { satpam, sopir) }\end{array}$ & 9,2 & 13,3 & 5,0 & 11,7 & 6,7 & 10,3 & 7,7 \\
\hline Not available* & 9,2 & 13,3 & 5,0 & 10,0 & 8,3 & 8,8 & 9,6 \\
\hline
\end{tabular}




\section{HASIL}

\section{Karakteristik Remaja dan Karakteristik Keluarga}

Contoh dalam penelitian ini adalah remaja berusia 15 sampai 18 tahun dengan persentase terbesar $(65 \%)$ berusia 16 tahun. Persentase terbesar ayah $(67,5 \%)$ dan ibu $(52,8 \%)$ terkategori dewasa madya. Rata-rata ayah dan ibu menempuh pendidikan selama sembilan tahun (jenjang SMP). Persentase terbesar (40\%) ayah bekerja sebagai wiraswasta, 18,3 persen ayah bekerja sebagai buruh, 17,5 persen ayah sebagai pegawai swasta, dan sisanya sebagai PNS, TNI/ABRI, pengacara, dosen, dan lainnya. Sementara itu, hampir tiga perempat $(74,2 \%)$ ibu sebagai ibu rumah tangga. Rata-rata jumlah anggota keluarga contoh sebanyak lima orang, yaitu sebagian besar (84,2\%) merupakan keluarga lengkap dan sisanya (15,8\%) merupakan keluarga tidak lengkap. Dari segi kepemilikan aset, sebagian besar (87,5\%) keluarga memiliki rumah yang berstatus milik sendiri, dan sisanya menyewa rumah atau menumpang. Sebanyak 67,5 persen keluarga memiliki kendaraan berupa motor sebanyak satu hingga dua unit. Seluruh keluarga contoh memiliki televisi, sebagian besar $(81,7 \%)$ keluarga memiliki sekitar satu hingga dua unit televisi, sisanya memiliki tiga hingga lima buah televisi. Lebih dua pertiga $(70,8 \%)$ keluarga tidak memiliki mobil. Hanya sebagian kecil $(0,8 \%)$ keluarga yang tidak memiliki telepon genggam. Sebanyak 40 persen keluarga memiliki satu hingga dua komputer dan sisanya tidak memiliki komputer. Perincian karakteristik remaja dan karakteristik keluarga disajikan pada Tabel 1.

Tabel 2 Skor rataan, minimum dan maksimum contoh berdasarkan variabel-variabel utama

\begin{tabular}{lcc}
\hline \multicolumn{1}{c}{ Variabel } & Rata-rata & Min-Maks \\
\hline Resiliensi & 76,8 & $48,6-94,4$ \\
Keterpaparan & 45,3 & $0,0-88,9$ \\
Keterlibatan & 22,6 & $0,0-66,7$ \\
Masalah & 42,5 & $11,1-88,9$ \\
Ancaman & 32,2 & $0,0-83,3$ \\
Kesejahteraan & 68,2 & $25-100,0$ \\
$\begin{array}{l}\text { subjektif } \\
\text { Protektif internal }\end{array}$ & 67,8 & $8,3-97,2$ \\
Protektif & & $35,8-93,3$ \\
pengasuhan orang & 67,2 & \\
tua & & \\
Protektif keluarga & 67,5 & $49,4-85,6$ \\
Protektif sekolah & 74,7 & $42,5-100,0$ \\
Protektif teman & 81,2 & $2,5-100,0$ \\
Protektif masyarakat & 69,9 & $0,0-100,0$ \\
\hline
\end{tabular}

\section{Resiliensi Remaja dan Faktor-faktor Ekologi}

Resiliensi remaja dalam penelitian ini diukur dari aspek kerjasama dan komunikasi, efikasi diri, empati, kemampuan memecahkan masalah, self-awareness, serta tujuan dan aspirasi. Variabel keterpaparan menggambarkan tingkat keterpaparan remaja terhadap perilaku menyimpang atau kenakalan di sekitar remaja yakni pernah melihat orang lain merokok, membolos, tawuran, mengonsumsi minuman keras, narkoba, termasuk pengalaman pernah mengalami pelecehan seksual, penganiayaan/kekerasan, dan sering terjadi tindak kejahatan atau kriminalitas di lingkungan sekitar tempat tinggal. Variabel keterlibatan menggambarkan keterlibatan remaja terhadap perilaku menyimpang atau kenakalan yakni merokok, membolos, tawuran, mengonsumsi minuman keras, menggunakan narkoba, dan melakukan seks bebas. Variabel masalah yang dihadapi oleh remaja menggambarkan permasalahan dalam kehidupan remaja, mencakup sering terjadi pertengkaran di rumah, keluarga sering mengalami kesulitan keuangan, pernah dijauhi teman-teman, pernah ditinggal orang yang dikasihi, pernah mendapat bencana atau musibah yang berat, pernah menderita penyakit berat, pernah tinggal kelas, pernah dihukum oleh guru di sekolah, memiliki kekurangan fisik yang dapat menjadi hambatan dalam melakukan aktivitas. Variabel ancaman berupa ajakan atau paksaan dari lingkungan untuk terlibat perilaku kenakalan.

Tabel 3 Koefisien korelasi antar variabel utama dengan resiliensi

\begin{tabular}{|c|c|}
\hline $\begin{array}{c}\text { Variabel dan Sub- } \\
\text { Variabel }\end{array}$ & Koefisien Korelasi \\
\hline Keterlibatan & $-0,225^{*}$ \\
\hline Pendapatan keluarga & $-0,207^{*}$ \\
\hline Lama pendidikan ayah & $-0,289^{*}$ \\
\hline Kesejahteraan subjektif & $0,274^{\star *}$ \\
\hline Protektif internal & $0,362^{*}$ \\
\hline - Penerimaan diri & $0,304^{* *}$ \\
\hline $\begin{array}{l}\text { - Penerimaan } \\
\text { lingkungan sekitar }\end{array}$ & $0,237^{* *}$ \\
\hline - Kepercayaan diri & $0,245^{\star *}$ \\
\hline - Prestasi & $0,281^{* *}$ \\
\hline - Disiplin & $0,378^{\star *}$ \\
\hline - Kemampuan diri & $0,228^{*}$ \\
\hline $\begin{array}{l}\text { Protektif pengasuhan } \\
\text { orang tua }\end{array}$ & $0,315^{*}$ \\
\hline - Parental acceptance & $0,425^{\star *}$ \\
\hline - Directive dimension & $0,276^{\star *}$ \\
\hline Protektif keluarga & $0,258^{* *}$ \\
\hline Protektif sekolah & $0,640^{* *}$ \\
\hline Protektif teman & $0,349^{* *}$ \\
\hline Protektif masyarakat & $0,415^{\star *}$ \\
\hline
\end{tabular}

Keterangan: ${ }^{* *}$ Signifikan pada $\mathrm{p}<0,01 ;{ }^{*}$ signifikan pada $\mathrm{p}<0,05$ 
Tabel 4 Sebaran koefisien regresi (terstandarisasi) pengaruh faktor-faktor ekologi terhadap resiliensi remaja

\begin{tabular}{|c|c|c|}
\hline \multirow{2}{*}{ Variabel Bebas } & \multicolumn{2}{|c|}{ Resiliensi } \\
\hline & $\beta$ & Sig. \\
\hline Keterpaparan & 0,036 & 0,655 \\
\hline Keterlibatan & $-0,085$ & 0,279 \\
\hline Masalah & $-0,006$ & 0,940 \\
\hline $\begin{array}{l}\text { Kesejahteraan } \\
\text { subjektif }\end{array}$ & 0,055 & 0,464 \\
\hline Ancaman & $-0,078$ & 0,320 \\
\hline Protektif internal & 0,177 & $0,025^{\star}$ \\
\hline $\begin{array}{l}\text { Protektif } \\
\text { pengasuhan } \\
\text { orang tua }\end{array}$ & 0,199 & $0,035^{\star}$ \\
\hline $\begin{array}{l}\text { Protektif } \\
\text { keluarga }\end{array}$ & $-0,092$ & 0,356 \\
\hline Protektif sekolah & 0,429 & $0,000^{* *}$ \\
\hline Protektif teman & $-0,016$ & 0,851 \\
\hline $\begin{array}{l}\text { Protektif } \\
\text { masyarakat }\end{array}$ & 0,145 & 0,149 \\
\hline $\begin{array}{l}\text { Wilayah } \\
\text { administratif }\end{array}$ & $-0,014$ & 0,856 \\
\hline Jenis kelamin & $-0,151$ & 0,072 \\
\hline Jenis sekolah & $-0,155$ & $0,033^{*}$ \\
\hline $\mathrm{F}$ & & \\
\hline Sig. & & \\
\hline$R$ Square & & \\
\hline $\begin{array}{l}\text { Adjusted } R \\
\text { Square }\end{array}$ & & \\
\hline
\end{tabular}

Tabel 2 menunjukkan bahwa nilai skor maksimum variabel keterpaparan, masalah, dan ancaman mencapai lebih dari 80 dengan skor rataan di atas 30 . Skor rataan menggambarkan rata-rata skor yang diperoleh oleh contoh. Tabel ini menggambarkan bahwa skor rata-rata keterpaparan, masalah, dan ancaman cukup tinggi, yang berarti rata-rata contoh banyak mengalami keterpaparan, masalah, dan ancaman perilaku menyimpang atau kenakalan. Akan tetapi, rata-rata contoh juga memiliki skor rata-rata resiliensi yang cukup tinggi, semakin tinggi skor resiliensi menggambarkan semakin tingginya resiliensi contoh.

\section{Korelasi Resiliensi Remaja dan Faktor- Faktor Ekologi}

Hasil uji korelasi (Tabel 3), menunjukkan bahwa kesejahteraan subjektif, protektif internal (pengasuhan yang dilakukan orang tua, lingkungan keluarga, lingkungan sekolah, faktor teman, dan lingkungan masyarakat) berhubungan positif dengan resiliensi remaja. Hal tersebut bermakna bahwa peningkatan variabel-variabel tersebut diharapkan dapat meningkatkan resiliensi remaja. Sementara itu, hasil uji hubungan antar variabel utama dan karakteristik remaja dan keluarga menunjukkan bahwa keterlibatan remaja dalam kenakalan remaja, pendapatan keluarga, dan lama pendidikan ayah, berhubungan negatif dengan resiliensi remaja.

\section{Pengaruh Faktor-Faktor Ekologi Terhadap Resiliensi Remaja}

Hasil uji regresi (Tabel 4) menunjukkan bahwa model yang diteliti menjelaskan sebanyak 47,3 persen factor-faktor yang memengaruhi resiliensi remaja sedangkan sebanyak 52,7 persen diteliti oleh variabel lain yang tidka diteliti. Faktor protektif yang berpengaruh secara signifikan terhadap resiliensi remaja adalah faktor protektif internal remaja $(\beta=0,177, \quad p=0,025)$, faktor protektif pengasuhan orang tua $(\beta=0,199, p=0,035)$, dan faktor protektif yang berasal dari sekolah $(\beta=0,429, p=0,000)$. Hasil juga menunjukkan bahwa faktor protektif pengasuhan orang tua memiliki pengaruh positif terhadap resiliensi remaja. Berdasarkan hasil tersebut, dilakukan pula analisis regresi antar komponen dari protektif pengasuhan orang tua yang terdiri dari parental acceptance, agresivitas, keacuhan, undifferentiated rejection, directive dimension, and emotional dimension. Hasil uji tersebut menunjukkan bahwa pola pengasuhan parental acceptance merupakan komponen yang paling berpengaruh positif signifikan terhadap resiliensi remaja $(\beta=0,398$, $\left.\mathrm{p}=0,000^{* *}\right)$.

Tabel 5 Sebaran koefisien regresi (terstandarisasi) pengaruh antara komponen protektif keluarga terhadap resiliensi remaja

\begin{tabular}{lrr}
\hline \multirow{2}{*}{ Variabel Bebas } & \multicolumn{2}{c}{ Resiliensi } \\
\cline { 2 - 3 } Kohesi & 0,215 & $\mathbf{0 , 0 4 5 ^ { * }}$ \\
Ekspresi & 0,059 & 0,543 \\
Konflik & $-0,160$ & 0,110 \\
Kebebasan & $-0,013$ & 0,896 \\
Orientasi prestasi & 0,175 & $\mathbf{0 , 0 4 8}$ \\
Orientasi intelektual & $-0,119$ & 0,217 \\
budaya & $-0,078$ & 0,388 \\
Orientasi rekreasi aktif & 0,224 & $\mathbf{0 , 0 3 2}$ \\
Orientasi moral religi & 0,176 & 0,108 \\
Organisasi & $-0,079$ & 0,439 \\
Kontrol & \multicolumn{2}{c}{3,943} \\
\hline$F$ & \multicolumn{2}{c}{0,000} \\
Sig & \multicolumn{2}{c}{0,266} \\
$R$ Square & \multicolumn{2}{c}{0,198} \\
Adjusted $R$ Square & \multicolumn{2}{c}{} \\
\hline Keterangan: ${ }^{*}$ Signifikan pada & $\mathrm{p}<0,01 ;{ }^{*}$ signifikan pada \\
p<0,05 & \multicolumn{2}{c}{}
\end{tabular}


Terdapat perbedaan hasil uji hubungan (Tabel 3 ), yang menunjukkan bahwa faktor protektif keluarga berhubungan positif dengan resiliensi, namun hasil uji regresi (Tabel 4) menunjukkan bahwa faktor protektif keluarga tersebut tidak berpengaruh terhadap resiliensi. Oleh karena itu, untuk mendalami hasil uji regresi dari faktor protektif keluarga yang tidak berpengaruh terhadap resiliensi, maka dilakukan uji khusus antara komponen protektif keluarga terhadap resiliensi. Hasil analisis (Tabel 5) menunjukkan bahwa kohesi $(\beta=0,215)$, orientasi untuk berprestasi $(\beta=0,175)$, dan orientasi terhadap moral religi $(\beta 0,224)$ merupakan komponen protektif keluarga yang paling berpengaruh terhadap resiliensi remaja.

\section{PEMBAHASAN}

Hasil penelitian ini menunjukkan bahwa keterlibatan remaja dalam kenakalan, pendapatan keluarga, dan lama pendidikan ayah berhubungan negatif dengan resiliensi remaja. Hal ini memperlihatkan pola bahwa semakin tinggi keterlibatan remaja dalam kenakalan, pendapatan keluarga, dan lama pendidikan ayah, terdapat kecenderungan resiliensi remaja semakin rendah. Mengacu hasil berbagai penelitian (Sunarti 2013b; Sunarti 2015) pendidikan lebih tinggi membawa seseorang bekerja secara formal dengan jam kerja yang lebih lama dan pendapatan yang lebih besar. Jam kerja yang lebih lama diduga berkaitan dengan sedikitnya interaksi ayah untuk membangun resiliensi remaja. Hasil penelitian ini menemukan bahwa faktor protektif keluarga berhubungan positif dengan resiliensi remaja. Didukung oleh temuan Youngblade, et al. (2007) bahwa karakteristik keluarga yang positif berhubungan dengan kompetensi sosial dan self-esteem remaja, serta menurunkan masalah perilaku internal dan eksternal serta menurunkan masalah akademis.

Hasil penelitian ini juga menunjukkan bahwa faktor protektif masyarakat berhubungan positif dengan resiliensi remaja, artinya dengan lingkungan masyarakat yang positif mendorong remaja memiliki resiliensi yang baik terhadap paparan atau ancaman perilaku menyimpang. Didukung oleh penelitian Fagan, Wright, dan Pichevsky (2014) menemukan bahwa remaja yang tinggal di lingkungan pertetanggaan dengan kolektivitas yang lebih tinggi memiliki dampak penggunaan obatobatan yang lebih rendah dibandingkan dengan remaja yang tinggal di lingkungan pertetanggaan dengan kolektivitas rendah.
Selanjutnya, hasil juga menunjukkan hubungan positif antara faktor protektif sekolah dan resiliensi remaja. Hasil ini didukung oleh penelitian Esteban dan Marti (2014) membuktikan bahwa siswa dengan tingkat resiliensi yang tinggi dan kemampuan akademik yang baik, akan mampu memiliki perkembangan kehidupan yang lebih positif meski berada dalam situasi lingkungan yang rentan. Sebaliknya, remaja yang memiliki risiko tinggi cenderung memiliki resiliensi psikologis yang lebih rendah (Anghel, 2015). Penelitian ini juga menemukan bahwa kesejahteraan subjektif berhubungan positif dengan resiliensi remaja. Didukung oleh Berg et al. (2013) menyatakan bahwa banyaknya perubahan yang terjadi dalam kehidupan remaja sangat berpengaruh terhadap proses penyesuaian diri yang berdampak pada kesejahteraan subjektif remaja. Hasil ini dapat dimaknai bahwa kemampuan remaja dalam mengelola perubahan dalam hidupnya (resiliensi) berdampak pada kesejahteraan subjektif remaja.

Faktor protektif dalam teorinya memiliki keterkaitan positif dengan perkembangan resiliensi remaja. Dalam penelitian ini, faktor protektif yang berpengaruh terhadap resiliensi remaja adalah faktor protektif internal remaja, faktor protektif pengasuhan orang tua, dan faktor protektif yang berasal dari sekolah. Temuan dari penelitian ini bahwa faktor protektif internal berhubungan positif dengan resiliensi remaja sesuai dengan penelitian Albuquerque et al., (2015) menunjukkan adanya hubungan antara resiliensi, selfesteem, konsep diri, dan kompetensi sosial. Didukung oleh temuan Aunillah dan Adiyanti (2015), bahwa resiliensi berhubungan positif dengan self-esteem. Karakter sifat yang dimiliki oleh remaja juga merupakan faktor protektif dalam membantu menjaga kesehatan mental anak (Witt, et al., 2014). Selain itu, pemahaman akan lingkungan, pengembangan pribadi, serta penerimaan diri juga terbukti berhubungan positif dengan resiliensi (Sagone \& De Caroli, 2014). Hal ini berkaitan dengan temuan Wang, Liu, dan Xin (2014) bahwa seorang individu berupaya mendapatkan dukungan sosial dari keluarga, masyarakat, dan layanan sosial untuk memfasilitasi perkembangan resiliensinya. Temuan penelitian juga sesuai dengan temuan Hartuti dan Mangunsong (2009), bahwa faktor protektif internal berpengaruh positif terhadap resiliensi akademis, bahwa faktor yang paling berpengaruh adalah efikasi diri. Lebih lanjut, Cortina et al. (2016) menjelaskan bahwa salah satu faktor kunci yang menentukan resiliensi 
adalah interpretasi kognitif (bagaimana remaja menginterpretasikan dunia di sekitar mereka). Penelitiannya menunjukkan bahwa anak-anak yang memiliki interpretasi kognitif yang positif terhadap lingkungan sekolah juga memiliki fungsi psikologis yang lebih baik pada skala depresi, kecemasan, dan dampak dari peristiwa traumatis. Sebaliknya, ketidakmampuan penyesuaian anak yang lebih besar berkaitan dengan kemampuan kognitif anak yang lebih rendah (Luthar, Cushing, Merikangas, dan Rounsaville, 1998). Didukung oleh penelitian Vanderbilt-Adriance dan Shaw (2008) menemukan bahwa tingkat inteligensi anak berkaitan positif dengan rendahnya perilaku antisosial dan tingginya kemampuan sosial anak.

Hasil penelitian juga menunjukkan bahwa faktor protektif pengasuhan orang tua berhubungan positif dengan resiliensi. Winston dan Chicot (2016) menemukan tanpa kelekatan yang baik antara orang tua dan anak sejak bayi, anak akan kesulitan untuk tumbuh dan berkembang sebagai anak yang bahagia, mandiri, dan memiliki resiliensi yang baik. Hubungan yang supportive dalam keluarga dan lingkungan keluarga yang stabil berkaitan dengan resiliensi (Afifi \& MacMillan, 2011). Keluarga dengan tingkat orientasi percakapan yang tinggi, yaitu orang tua percaya bahwa komunikasi adalah sarana untuk mendidik dan bersosialisasi dengan remaja, anggota keluarga sering bercakap-cakap secara bebas, orang tua memegang nilai untuk saling bertukar ide antar anggota keluarga, maka remaja yang dihasilkan adalah mereka yang mampu menunjukkan interaksi yang baik dengan lingkungan sekitarnya. Temuan ini juga sesuai dengan beberapa penelitian sebelumnya, bahwa komunikasi positif antara orang tua dan anak di kalangan remaja membantu mengurangi kemungkinan keterpaparan terhadap kekerasan yang akan mengakibatkan gejala depresi (Elsman, et.al, 2015). Temuan Jowkar et al. (2011) turut menunjukkan adanya hubungan pola komunikasi keluarga dan resiliensi akademis. Keterlibatan keluarga dapat meminimalisir dampak negatif dari perilaku menyimpang anak (Schlauc et al., 2013). Dampak negatif pengalaman yang diperoleh pada masa kanakkanak juga secara substansif dapat dikurangi dengan dukungan dari orang dewasa yang dipercayai oleh remaja, termasuk orang tua (Bellis et al., 2017). Sementara anak-anak yang mengalami kekerasan dan diasuh oleh orang tua yang emosinya kurang stabil cenderung kesulitan untuk membangun resiliensi (Jaffee \& Gallop, 2007).
Faktor protektif lainnya, yakni sekolah merupakan salah satu faktor cukup besar pengaruhnya terhadap resiliensi remaja. Lee dan Stewart (2013) mengemukakan bahwa sekolah dan guru memiliki peranan penting dalam membangun resiliensi. Resiliensi dapat terbentuk melalui adanya lingkungan sekolah yang penuh dengan kepedulian dan kehangatan, adanya harapan yang tinggi dalam pencapaian prestasi dan perilaku yang diberikan sekolah kepada remaja, serta adanya kesempatan bagi remaja untuk terlibat aktif berkontribusi dalam setiap kegiatan bermakna di sekolah. Penelitian Alm dan Laftman (2016) turut menunjukkan para siswa yang tergabung dalam kelas dengan iklim berorientasi masa depan yang positif, ikut terpengaruh oleh iklim positif tersebut sehingga lebih sedikit terlibat dalam perilaku negatif. Keterlibatan guru juga berpengaruh dalam melindungi siswa dari inisiasi perilaku menyimpang dan kenakalan di sekolah (Earnshaw, et al., 2014). Beberapa program peningkatan resiliensi dan kesehatan mental yang dilakukan dengan melibatkan sekolah mampu meningkatkan resiliensi dan faktor protektif, mengurangi penggunaan alkohol, rokok, dan obat terlarang, serta mengurangi risiko gangguan mental pada remaja (Hodder, et al., 2011; Dray, et al., 2014). Bersekolah juga terbukti dapat meningkatkan perilaku adaptif/prososial anak-anak (Betancourt, et al., 2010).

Hasil analisis dalam penelitian ini juga menunjukkan bahwa faktor teman berhubungan positif dengan resiliensi remaja namun menunjukkan arah pengaruh yang negatif dengan tidak menunjukkan adanya pengaruh yang signifikan. Temuan ini sesuai dengan pendapat Bogenschneider (1998) bahwa peer group atau teman sebaya dapat menjadi faktor pelindung juga dapat menjadi faktor risiko bagi remaja. Teman dapat menjadi faktor risiko apabila remaja berhubungan dengan teman-teman yang terlibat dalam masalah perilaku. Bergaul dengan teman sebaya yang menyimpang meningkatkan kemungkinan remaja juga ikut terlibat dalam perilaku berisiko. Teman sebaya dapat menjadi faktor protektif ketika teman tersebut adalah teman dekat yang dapat membantu jika dibutuhkan dan menjadi tempat untuk menceritakan masalah. Remaja yang memiliki teman dekat memiliki kemungkinan untuk dapat berhasil beradaptasi menghadapi situasi tertekan.

Berkaitan dengan pengasuhan orang tua, semakin tingginya penerimaan, kehangatan, 
dan afeksi yang diberikan orang tua maka akan semakin tinggi pula resiliensi remaja. Sesuai dengan penelitian Ogelman (2015), bahwa kehangatan dan afeksi yang diberikan ibu dan ayah terhadap remaja secara signifikan dapat menjadi penentu resiliensi remaja. Pengasuhan yang positif salah satunya dibangun oleh optimisme Ibu terhadap pengasuhan yang dilakukan (Ellingsen, Baker, Blacher, dan Crnick, 2014). Temuan ini menunjukkan bahwa pola pengasuhan yang mengambarkan dukungan orang tua, penuh penerimaan orang tua terhadap remaja, afeksi dan kasih sayang yang diberikan orang tua dapat menguatkan anak untuk menghadapi berbagai ancaman, bahaya, maupun tekanan faktor risiko lainnya dan menjadikan mereka semakin resilien. Berdasarkan hasil analisis regresi antar komponen dari protektif pengasuhan orang tua, parental acceptance merupakan komponen yang memiliki pengaruh positif signifikan terhadap resiliensi remaja. Hubungan positif antara remaja dengan orang dewasa di sekitarnya berpengaruh terhadap kesuksesan anak di sekolah dan memiliki kemungkinan yang lebih kecil untuk terpapar dan terlibat dalam kekerasan (Culyba, et al., 2016).

Faktor protektif keluarga berkorelasi dengan resiliensi, namun tidak berpengaruh nyata dalam uji regresi. Untuk mendalami hal tersebut, dilakukan ujipengaruh khusus komponen protektif keluarga terhadap resiliensi. Hasilnya menunjukkan bahwa kohesi, orientasi untuk berprestasi, dan orientasi terhadap moral dan religi merupakan komponen protektif keluarga yang paling berpengaruh terhadap resiliensi remaja. Hal tersebut bermakna bahwa resiliensi remaja dapat ditingkatkan melalui peningkatan kohesi, orientasi berprestasi, dan orientasi terhadap moral dan religi di dalam keluarga. Hal tersebut sesuai dengan tiga kunci proses kelentingan menurut Walsh (2006) yang menyatakan bahwa komunikasi yang merupakan bagian dari kohesi atau hubungan, kepercayaan terhadap Tuhan, dan organisasi di dalam keluarga merupakan komponen utama yang dapat membangun resiliensi individu.

Orientasi terhadap moral religi dalam penelitian ini diukur melalui persepsi individu terkait seberapa sering anggota keluarga mengunjungi tempat ibadah, seberapa percaya keluarga terhadap sesuatu yang harus diyakini dalam hidup, seberapa penting kitab suci di rumah, dan apabila anggota keluarga memiliki pemikiran yang kuat tentang sesuatu yang benar atau salah. Orientasi pada agama merupakan salah satu faktor yang dapat meningkatkan resiliensi individu menghadapi faktor risiko. Individu yang menyakini adanya Tuhan dan percaya bahwa segala sesuatu yang terjadi dalam hidup ini merupakan kehendak Tuhan maka akan semakin mudah untuk bangkit dari keterpurukan setelah menghadapi berbagai tekanan. Kepercayaan terhadap agama dapat memfasilitasi perkembangan resiliensi seorang individu (Wang, Liu, \& Xin, 2014). Sesuai dengan temuan Kasen, Wickramaratne, Gameroff, dan Weissman (2012), bahwa religiusitas berkontribusi terhadap perkembangan resiliensi pada individu yang berisiko. Orientasi keagamaan biasanya ditunjukkan dengan partisipasi individu dalam kegiatan kagamaan dan individu yang lebih agamis memiliki selfesteem dan perilaku yang lebih positif dalam hidup. Selain itu, individu yang berorientasi pada agama juga lebih jarang mengalami depresi atau jarang merasa hidup tidak bermakna dan juga memiliki perasaan terhadap suatu tujuan yang kuat. Remaja yang memiliki tingkat religiusitas yang baik juga terbukti memiliki motivasi berprestasi yang tinggi dan cenderung lebih mudah merencanakan masa depan (Susanti, 2016). Sesuai pula dengan review Eriksson et al. (2010), bahwa kepercayaan terhadap agama merupakan salah satu faktor protektif bagi remaja.

Berdasarkan hasil-hasil yang diperoleh dari penelitian ini, terdapat beberapa aksi prioritas yang dapat dilakukan oleh pihak-pihak terkait untuk meminimalisir atau mencegah dampak ancaman terhadap remaja. Pertama, menyusun pemetaan ancaman atau bahaya di lingkungan utama remaja yakni keluarga, sekolah, dan masyarakat. Kedua, menambahkan porsi agama dalam proses pendidikan remaja serta penekanan lebih mengenai doktrin-doktrin agama mengenai perilaku baik-buruk, pahala-dosa, serta pemahaman mendalam bahwa setiap perbuatan pasti memiliki konsekuens. Ketiga, memberikan porsi cukup bagi acara-acara televisi yang menggambarkan kemajuan remaja; dan membuat forum infrastruktur sosial untuk menyatukan semua organisasi milik pemerintah maupun binaan pemerintah yang akan diperkuat lintas kerjasamanya.

Kepada keluarga, diharapkan meningkatkan pengetahuan dan praktek pengasuhan penerimaan dan arahan, meningkatkan ketahanan keluarga untuk memenuhi peran, fungsi, dan tugas keluarga didalamnya 
termasuk tugas perkembangan anak remaja, meningkatkan pengetahuan dan kesiapsiagaan terhadap hal hal yang menjadi ancaman kepada remaja dari berbagai lingkungan, meningkatkan kerjasama dengan berbagai pihak (sekolah, masyarakat) untuk melindungi remaja, meningkatkan partisipasi dan keterlibatan dalam berbagai kegiatan yang meningkatkan kelentingan remaja yang diadakan berbagai pihak sekolah, dan membangun lingkungan pertetanggan dan masyarakat juga sekolah yang membangun. Kepada sekolah, disarankan untuk meningkatkan efektivitas pendidikan di sekolah, memberi perhatian dan menangani anak remaja yang rentan dengan memadai, mencegah peluang keterpaparan remaja oleh situasi yang mengganggu, bekerjasama dengan semua pihak, khususnya orang tua dalam pengawasan dan perlindungan remaja. Kepada masyarakat, disarankan untuk meningkatkan kepedulian terhadap remaja di lingkungan, membangun kebersamaan melindungi remaja dari berbagai ancaman di lingkungan; mengembangkan, memelihara keakraban dan saling menjaga, melaksanakan program pembangunan resiliensi anak, mencegah masuknya hal-hal yang dapat meningkatkan keterpaparan remaja terhadap situasi mengganggu / merusak / membahayakan;dan menyediakan sistem pendukung bagi keluarga yang membutuhkan terkait pengasuhan, pengawasan, perlindungan remaja. Kepada pemerintah, disarankan untuk menyusun rencana aksi prioritas, bersinergi dengan berbagai pihak untuk melakukan upaya terobosan perlindungan remaja, melakukan perubahan paradigma dalam penetapan kebijakan dan program dari penanganan yang bersifat kuratif (penyelesaian kasus) dan menggeser sember daya kepada penanganan faktor-faktor perlindungan remaja yang bersifat hulu atau pencegahan. Kepada Peneliti, untuk melanjutkan penelitian kelentingan remaja dengan lingkup yang lebih luas dan dengan menggunakan analisis yang lebih komprehensif.

\section{SIMPULAN DAN SARAN}

Penelitian ini menghasilkan beberapa temuan penting diantaranya adalah bahwa resiliensi remaja berkorelasi dengan seluruh aspek protektif internal yaitu penerimaan diri, penerimaan lingkungan, kemampuan diri, kepercayaan, disiplin, dan prestasi. Resiliensi remaja berhubungan dengan pengasuhan dimensi kehangatan dan arahan, dan protektif lingkungan keluarga. Resiliensi remaja dipengaruhi oleh faktor pembinaan dan perlindungan yang dilakukan sekolah, oleh pengasuhan orang tua di rumah, dan faktor internal remaja. Sekolah menyediakan lingkungan yang meningkatkan resilensi remaja, sementara pengasuhan yang berpengaruh kuat adalah pengasuhan dimensi kehangatan. Analisis pengaruh khusus protektif lingkungan keluarga menunjukkan bahwa orientasi moral-religi, kohesi, dan orientasi prestasi berpengaruh positif terhadap resiliensi.

Peneliti merekomendasikan kepada para pihak (keluarga, sekolah, masyarakat, pemerintah, peneliti) di wilayah remaja berada untuk bekerjasama saling melengkapi dan saling menguatkan melakukan berbagai upaya perlindungan remaja dengan intensitas yang memadai dan dilakukan secara berkelanjutan, dengan mengutamakan upaya pencegahan, karena perlindungan terbaik remaja adalah melalui pencegahan.

\section{DAFTAR PUSTAKA}

Afifi, T. O., \& Macmillan, H. L. (2015). Resilience following child maltreatment: a review of protective factors. The Canadian Journal of Psychiatry, 56(5) 266-272.

Albuquerque, C., Almeida, J., Cunha, M., Madureira, A., \& Andrade, A. (2015). Protective resilience factors in institutionalized Portuguese adolescents. Procedia Social and Behavioral Sciences 171, 276-283.

Alm, S., \& Laftman, S. B. (2016). Future orientation climate in the school class: relations to adolescent delinquency, heavy alcohol use, and internalizing problems. Children and Youth Services Review, 70, 324-331.

Anghel, R. E. (2015). Psychological and educational resilience in high vs. low-risk Romanian adolescents. Procedia Social and Behavioral Sciences, 203, 153-157.

Aunillah, F., \& Adiyanti, M. G. (2015). Program pengembangan keterampilan resiliensi untuk meningkatkan self-esteem pada remaja. Gadjah Mada Journal of Professional Psychology 1(1), 48-63.

Bellis, M. A., Hardcastle, K., Ford, K., Hughes, K., Ashton, K., Quigg, Z., \& Butler, N. (2017). Does continuous trusted adult support in childhood impart life-course resilience against adverse childhood experiences-a retrospective study on 
adult health-harming behaviours and mental well-being. BioMed Central Psychiatry 17(1), 110-121.

Benard, B. (1995). Fostering resilience in children. Terhubung dari ERIC Digest. IL: ERIC Clearinghouse on Elementary and Early Childhood Education. [ED386327]

Berg, H. V., George, A.A., Edwin, D.P., Anja, B., Basson, N., Marisa, D.V., \& Solomon, M. (2013). The pivotal role of social support in the well-being of adolescents. Well-Being Research, 4, 315-339.

Betancourt, T. S., Brennan, R.T., Rubin-Smith, J., Fitzmaurice, G.M., \& Gilman, S.E. (2010). Sierra Leone's former child soldiers: a longitudinal study of risk, protective factors, and mental health. Journal of American Academy of Child and Adolescence Psychiatry 49(6), 606615.

Bronfenbrenner, U. (1979). The ecology of human development. Massachusetts, US: Harvard University Press.

Brooks, J. E. (2006). Strengthening resilience in children and youths: maximizing Opportunities through the schools. Children Schools, 28(2), 69-76.

Cortina, M.A, Stein A., Kahn, K., Hlungwani, T.M., Holmes, E.A., \& Fazel, M. (2016). Cognitive styles and psychological functioning in rural South Africal school students: understanding influences for risk and resilience in the face of chronic adversity. Journal of Adolescents, 49, 38-46.

Culyba, A. J., Ginsburg, K. R., Branas, C.C., Richmond, T.S., \& Wiebe, D.J. (2016). Protective effects of adolescent-adult connection on male youth in urban environment. Journal of Adolescent Health, 58(2), 237-240.

Dray, J., Bowman, J., Freund, M., Campbell, E., Wolfenden, L., Hodder, R. K., \& Wiggers, J. (2014). Improving adolescent mental health and resilience through a resilience-based intervention in schools: study protocol for a randomized controlled trial. Trials, 15, 289-297.

Earnshaw, V. A., Roshental, L., Carroll-Scott, A., Peters, S. M., McCaslin, C., \& Ickovics, J. R. (2014). Teacher involvement as a protective factor from the association between race-based bullying and smoking initiation. Social
Pscyhology of Education, 17(2), 197209.

Ellingsen, R., Baker, B. L., Blacher, J., \& Crnic, K. (2014). Resilient parenting of children at developmental risk accros middle childhood. Research in Developmental Disabilities, 35(6), 1364-1374.

Elsman, A. B., Stoddard, S. A., Heinze, J., Caldwell, C. H., \& Zimmerman, M. A. (2015). Depressive symptoms, social supports, and violence exposure among urban youth: a longitudinal studies of resilience. Developmental Psychology, 51(9), 1307-1316.

Eriksson, I., Cater, A., Andershed, A., \& Andershed, H. (2010). What we know and need to know about factors that protect youth from problems: a review of previous reviews. Procedia Social and Behavioral Sciences, 5, 477-482.

Esteban, M. P. S., \& Marti, A. S. (2014). Beyond compulsory schooling: resilience and academic success of immigrant youth. Procedia Social and Behavioral Sciences, 132, 19-24.

Fagan, A. A., Wright, E. M., \& Pinchevsky, G. M. (2014). The protective effects of neighborhood collective efficacy on adolescent substance use and violence following exposure to violence. Journal of Youth Adolescence, 43(9), 14981512.

Gunarsa, S. D., \& Gunarsa, Y. (1995). Psikologi praktis: anak remaja dan keluarga. Jakarta, ID: BPK Gunung Mulia.

Hartuti, \& Mangunsong, F. M. (2009). Pengaruh faktor-faktor protektif internal dan eksternal pada resiliensi akademis siswa penerima bantuan khusus murid miskin (BKMM) di SMA Negeri Depok. Jurnal Psikologi Indonesia, 6,107-119.

Hicks, B. M., Johnson, W., Durbin, E., Blonigen, D. M., lacono, W. G., \& McGue, M. (2013). Gene-environment correlation in the development of adolescent substance abuse: selection effects of child personality and mediation via contextual risk factors. Developmental Psychology, 25(1), 119132.

Hodder, R. K., Daly, J., Freund, M., Bowman, J. Hazell, T., \& Wiggers, J. (2011). A school-based resilience intervention to decrease tobacco, alcohol, and marijuana use in high school students. 
BioMed Central Public Health, 11, 722731. doi: https://doi.org/10.1186/14712458-11-722.

Jaffee, S. R., \& Gallop, R. (2007). Social, emotional, and academic competence among children who have had contact with child protective services: prevalence and stability estimates. Journal of American Academy of Child and Adolescent Psychiatry, 46(6), 757-765.

Jowkar, B., Kohoulat, N., \& Zakeri, H. (2011). Family communication patterns and academic resilience. Procedia Social and Behavioral Sciences, 20, 87-90.

Kalil, A. (2013). Family Resilience and Good Child Outcomes. A Review of a Literature. Wellington: Centre for Social Research and Evaluation. Diambil dari http://www.citeseerx.ist.psu.edu/viewdoc.

Kaplan, H. B. (1999). Toward an understanding of resilience: a critical review of definitions and models in resilience and development: positive life adaptations. New York, US: Kluwer Academic/Plenum Publisher.

LaFromboise, T.D., Hoyt, D.R., Oliver, L., \& Whitbeck, L. B. (2006). Family, community, and school influences on resilience among American Indian adolescent in the upper Midwest. Journal of Community Psychology, 32(2), 193209.

Lee, P. C., \& Stewart, D. E. (2013). Does a socio-ecological school model promote resilience in primary school. Journal of School Health, 8(11), 795-804.

Luthar, S. S., Cushing, G., Merikangas, K. R., Rounsaville, B. J. (1998). Multiple jeopardy: risk and protective factors among addicted mothers' offspring. Developmental Psychopathology, 10(1), 117-136.

MacLeod, S., Musich, S., Hawkins, K., Alsgaard, K., \& Wicker, E. (2016). The impact of resilience among older adults. Geriatric Nursing, 37, 266-272.

Masten, A. S. (2001). Ordinary magic: resilience process in development. Journal of American Psychologists, 56, 227-338.

Moos, B. S., \& Moos, R. H. (2009). Family environment scale. California, US: mind garden.

Diambil dari://www.mindgarden.com/products/fes cs.htm.
Kasen, S., Wickramaratne, P., Gameroff, M.J., \& Weissman, M. M. (2012). Religiosity and resilience in persons at high risk for major depression. Psychological Medicine, 42(3), 509-519.

Ogelman, H. G. (2015). Predictor effect of parental acceptance-rejection levels on resilience of preschool children. Procedia-Social and Behavioral Sciences, 174, 622-628.

Wang, P., Liu, D. Z., \& Xin, Z. (2014). The social ecology of resilience: a comparison of Chinese and Western researchers. Procedia Social and Behavioral Sciences, 116, 3259-3265.

Resnick, Michael. (2000). Protective factors, resiliency, and healthy youth development. Adolescent Medicine: State of the Art Reviews, 11, 157-164.

Sagone, E., \& De Caroli, M. E. (2014). Relationships between psychological well-being and resilience in middle and late adolescents. Procedia Social and Behavioral Sciences, 141, 881-887.

Schlauch, R.C., Levitt, A., Connel, C.M., \& Kaufman, J.S. (2013). The moderating effect of family involvement on substance use risk factors in adolescents with severe emotional and behavioral challenges. Addictive Behavior, 38(7), 2333-2342.

Sunarti, E. (2013a). Family kit. modul ketahanan keluarga. Bogor, ID: IPB Press.

(2013b). Tipologi Keluarga di Wilayah Perdesaan dan Perkotaan. Jurnal IImu Keluarga dan Konsumen, 6(2), 73-81. doi: http://dx.doi.org/10.24156/jikk.2013.6.2.7 3.

(2015). Ketahanan keluarga Indonesia dari kebijakan dan penelitian menuju tindakan. Buku Orasi IImiah Guru Besar IPB. Bogor, ID: IPB Press.

Susanti, R. (2016). Gambaran orientasi masa depan remaja dalam bidang pekerjaan ditinjau dari religiusitas dan motivasi berpestasi pada remaja Desa Sei Banyak Ikan Kelayang. Jurnal Psikologi, 12(1), 109-116.

Ungar, M. (2008). Resilience across cultures. British Journal of Social Work, 38, 218235.

Ungar, M., \& Liebenberg, L. (2011). Assessing resilience across cultures using mixed 
methods: Construction of the child and youth resilience measure. Journal of Mixed Method Research, 5(2), 126-149. doi:10.1177/1558689811400607.

Vanderbilt-Adriance, E., \& Shaw, D.S. (2008). Protective factors and the development of resilience in the context of neighborhood disadvantage. Journal of Abnormal Child Psychology, 36(6), 887901.

Wagnild, G. M., \& Young, H. M. (1993). Development and psychometric evaluation of the Resilience Scale. Journal of Nursing Measurement 1(2), 167-168.

Walsh, F. (2006). Strengthening Family Resilience (Second Edition). New York, US: The Guilford Press. Diambil dari http://winnebago.uwex.edu/.

Winfield, \& Linda F. (1994). Developing resilience in urban youth. Urban monograph series. Illinois, US: North Central Regional Educational Laboratory.

Winston, R., \& Chicot, R. (2016). The importance of early bonding on the longterm mental health and resilience of children. London Journal of Primary Care, 8(1), 12-14.

Witt, A., Schmid, M., Fegert, J. M., Plener, P.L., \& Goldbeck, L. (2014). Temperament and character-traits as protective factors among adolescents in juvenile residential facilities. Praxis der Kinderpsychologie und Kinderpsychiatry, 63(2), 114-129.

Youngblade, L. M., Theokas, C., Schulenberg, J., Curry, L., Huang, I., \& Novak, M. (2007). Risk and promotive factors in families, schools, and communities: a contextual model of positive youth development in adolescence. Pediatrics, 119, 47-53. 